\title{
ANALISIS BATAS TOLERANSI ALIGNMENT ANTARA POROS MOTOR LISTRIK DAN POROS FRESH WATER COOLING PUMP DI PT.PINDAD (PERSERO)
}

\author{
Soesanto \& Akhmad Farid \\ Jurusan Teknik Mesin Universitas Widya Gama Malang \\ Email : $\underline{\text { soesanto@pindad.com }}$
}

\begin{abstract}
ABSTRAK
Dalam perawatan mesin-mesin industri diperlukan pengetahuan yang memadai dan terperinci dalam pengetahuan tata cara pelurusan poros untuk mengatasi kerusakan pada mesin yang mengakibatkan pendeknya usia mesin tersebut. Oleh karena itu perlu dilakukan analisis pengambilan data untuk batas toleransi alignment antara poros motor listrik dan poros pompa.Tujuan dilakukan analisis ini untuk mengetahui toleransi alignment yang diijinkan antara poros motor listrik dan poros pompa, dengan kecepatan putaran motor listrik yaitu 2000 - 3000 (rpm). Serta untuk mengetahui besarnya penyimpangan ketidaklurusan offset dan angular yang terjadi antara poros motor listrik dan poros pompa yaitu pada pompa 1 diketahui bahwa nilai hasil perhitungan offset dan angular pada bidang vertikal yaitu 0,36 mm dan $0,97 \mathrm{~mm} / 100$. Sedangkan pada bidang horizontal nilainya yaitu $0,36 \mathrm{~mm}$ dan 0,017 mm/100. Kemudian pada pompa dua (2) diketahui bahwa nilai hasil perhitungan offset dan angular pada bidang vertikal yaitu 0,065 mm dan 0,609 mm/100. Sedangkan pada bidang horizontal nilainya yaitu 0,065 mm dan 0,01 mm/100. Maka perlu untuk dilakukan perbaikan reposisi terhadap kaki motor untuk mengurangi penyimpangan offset dan angular yang terjadi antara poros motor listrik dan poros pompa.
\end{abstract}

\section{Kata Kunci : perawatan, poros motor listrik, poros pompa, kesatusumbuan, reposisi}

\section{PENDAHULUAN}

Alignment adalah suatu pekerjaan atau proses mensimetriskan kedua objek atau sumbu poros sehingga sentris antara poros penggerak dengan sumbu poros yang digerakan dengan dua tumpuan saling berkaitan (Vietsch, 2011). Tetapi dalam kenyataannya pengertian lurus tidak bisa didapatkan $100 \%$ sehingga harus diberikan toleransi kurang dari $0,05 \mathrm{~mm}$, untuk mendapatkan kesentrisan antara kedua poros pemutaran dan poros yang diputar hingga tidak menimbulkan gesekan, getaran, dan faktor-faktor lainnya.

Alignment dapat meminimalisir atau menghindari kemungkinan terjadinya proses memperpendek umur sebuah mesin yang tentu akan mengurangi beban operasional perbaikan mesin anda. Kehandalan unit produksi suatu perusahaan yang didalamnya terdiri dari berbagai macam unit mesin sangatlah didambakan oleh seluruh pengelolanya dan ownernya, agar hasil produksi selalu mencapai target yang telah ditentukan.

Dalam dunia pendidikan sekarang ini pentingnya melakukan pengujian alignment pada praktek perawatan mesin industri menjadi hal yang perlu dilakukan. Hal ini disebabkan karena banyak jenis instalasi dan perlengkapan yang harus dihubungkan ke perlengkapan lain sebelum dapat dioperasikan, sebagaimana pompa, tidak dapat beroperasi sendiri.

Untuk beroperasi, pompa harus dihubungkan ke sebuah motor atau sumber tenaga lain. Oleh karena itulah, hubungan antara poros pompa dan poros motor merupakan hal yang sangat penting. Sedangkan fungsi kopling digunakan di sini adalah untuk meneruskan daya dan putaran dari poros penggerak ke poros yang digerakkan, dimana posisi sumbu poros yang dihubungkan oleh kopling tetap harus berada pada satu garis lurus. Agar kopling bekerja secara benar atau sempurna, komponen-komponennya harus berada dalam kondisi baik, dan perlengkapannya harus diluruskan secara tepat sehingga garis sumbu kedua poros tersebut membentuk satu garis lurus yang tidak terputus.

Penempatan kopling dan poros disebut pelurusan poros (shaft alignment). Posisi sumbu poros yang tidak berada pada satu garis lurus disebut dengan ketidaksesumbuan (misalignment). Ketidaksesumbuan kopling tetap akan mengakibatkan timbulnya getaran, getaran yang berlebihan dalam jangka waktu yang lama akan mengakibatkan kerusakan pada komponenkomponen mesin. Kondisi ketidaksesumbuan ini merupakan masalah yang sering terjadi pada instalansi mesin. Karena itu dalam perawatan pada mesin-mesin industri sangat diperlukan pengetahuan yang memadai dan terperinci dalam pengetahuan tata cara meluruskan antara poros motor dan pompa yang bertujuan untuk merawat dan mengatasi kerusakan pada mesin yang mengakibatkan pendeknya umur mesin tersebut.

Permasalahan yang dibahas dalam artikel ini adalah tentang besarnya penyimpangan yang biasa terjadi antara sumbu poros pompa dan poros 
motor, batas toleransi yang diijinkan, dan cara melakukan reposisi ketidaksesumbuan yang terjadi. Pengetahuan tentang cara penanganan permasalahan ini dapat digunakan untuk mengenali sebab-sebab ketidaksesumbuan poros, dan cara menjaga kinerja sistem pompa untuk tetap dalam kondisi handal, efisien dan terawat bagus.

\section{METODOLOGI}

Pelaksanaan analisis ketidaksesumbuan poros pompa dan poros motor dilakukan dengan cara mengambil data perawatan berkala terhadap beberapa jarak variabel ukur berikut :

Y : Rim dial (DIR) nilai bacaan total dari dial indikator disisi kopling.

F : Face dial (DIF) nilai bacaan total dari dial indikator dipermukaan kopling.

B : Jarak antara kaki dalam ke kopling driver.

C : Jarak antara kopling driver dan kopling driven.

$\mathrm{H}$ : Diameter kopling.

Data perawatan tersebut diambil dari 2 buah pompa yang digunakan pada motor and fresh water cooling pumps PT. Pindad (Persero). Datadata tersebut diolah sebagai data time series dan dianalisis mengikuti perhitungan beberapa parameter berikut :

\section{A. Offset dan Angular Mis-Alignment}

1) Pada Bidang Vertikal

$$
\begin{aligned}
& \text { Offset Mis - Alignment }=\frac{Y}{2} \\
& \text { Angular Mis - Alignment }=\tan ^{-1}\left(\frac{\mathrm{F}}{\mathrm{H}}\right)
\end{aligned}
$$

2) Pada Bidang Horizontal

$$
\begin{aligned}
& \text { Offset Mis - Alignment }=\frac{\mathrm{Y}}{2} \\
& \text { Angular Mis - Alignment }=\frac{\mathrm{F}}{\mathrm{H}}
\end{aligned}
$$

\section{B. Perhitungan Koreksi Alignment Horizontal}

Kaki Dalam Motor Penggerak $=\frac{F(B+C)}{H}-(Y)$

Kaki Luar Motor Penggerak $=\frac{F(A+B+C)}{H}-(Y)$

\section{Perhitungan Koreksi Alignment Vertikal}

$$
\begin{aligned}
& \text { Kaki Dalam Motor Penggerak }=\left[\left(\frac{F}{H}\right) B\right]+\frac{1}{2}(Y) \\
& \text { Kaki Luar Motor Penggerak }=\left[\left(\frac{F}{H}\right)(B+C)\right]+\frac{1}{2}(Y)
\end{aligned}
$$

\section{HASIL DAN PEMBAHASAN}

Posisi pengukuran ideal dari hubungan poros pompa dan poros motor ditunjukkan pada Gambar 1. Hasil pengukuran jarak kaki ditunjukkan pada Tabel 1. Hasil pembacaan dial indicator ditunjukkan pada Tabel 2. Hasil pengukuran kelurusan ditampilkan pada Tabel 3.

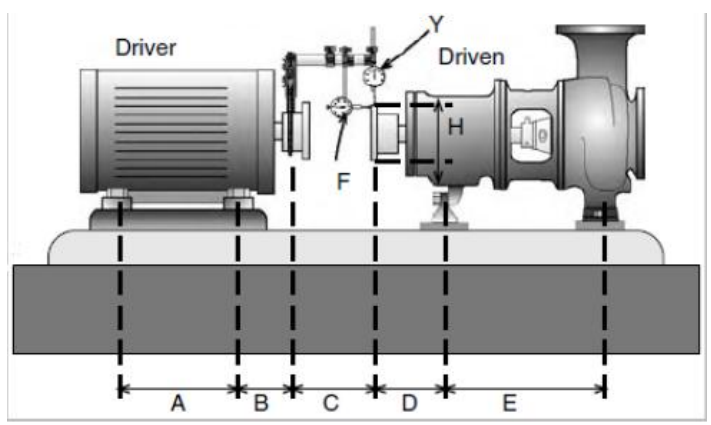

Gambar 1. Acuan pengukuran kaki motor, pompa dan kopling

\begin{tabular}{|c|c|c|c|c|c|c|c|}
\hline \multirow{2}{*}{ Item } & \multirow{2}{*}{ Deskripsi } & \multicolumn{3}{|c|}{ Pompa 1} & \multicolumn{3}{|c|}{ Pompa 2} \\
\hline & & Sep $(\mathrm{mm})$ & Okt (mm) & $\operatorname{Nov}(\mathbf{m m})$ & Sep (mm) & Okt (mm) & $\operatorname{Nov}(\mathbf{m m})$ \\
\hline $\mathrm{TF}$ & Top Axial & 0 & 0 & 0 & 0 & 0 & 0 \\
\hline $\mathrm{RF}$ & Right Axial & $+1,45$ & $+2,01$ & $+2,59$ & $+0,35$ & $+0,61$ & +0.82 \\
\hline LF & Left Axial & $-0,42$ & -0.47 & $+0,67$ & $+0,43$ & $+0,53$ & $+0,75$ \\
\hline $\mathrm{BF}$ & Bottom Axial & +1.03 & +1.54 & $+1,92$ & $+0,78$ & $+1,14$ & +1.57 \\
\hline TY & Top Radial & 0 & 0 & 0 & 0 & 0 & 0 \\
\hline $\mathrm{RY}$ & Right Radial & -0.25 & -0.28 & -0.30 & $+0,07$ & $+0,012$ & +0.2 \\
\hline LY & Left Radial & $+0,51$ & $+0,76$ & $+1,02$ & -0.02 & $-0,03$ & $-0,07$ \\
\hline BY & Bottom Radial & +0.26 & +0.48 & +0.72 & +0.05 & $+0,09$ & +0.13 \\
\hline
\end{tabular}
(Lawrence, 2009)

Tabel 1. Daftar Ukuran Acuan

\begin{tabular}{|c|c|l|c|}
\hline No & Item & \multicolumn{1}{|c|}{ Deskripsi } & Nilai (mm) \\
\hline 1 & A & Jarak Antara Kaki Luar Dan Kaki Dalam Driver & 210 \\
\hline 2 & B & Jarak Antara Kaki Dalam Ke Kopling Driver & 180 \\
\hline 3 & C & Jarak Antara Kopling Driver Dan Kopling Driven & 45 \\
\hline 4 & D & Jarak Antara Kopling Dan Kaki Dalam Driven & 75 \\
\hline 5 & E & Jarak Antara Kaki Dalam Dan Kaki Luar Driven & 260 \\
\hline 6 & H & Diameter Kopling & 110 \\
\hline
\end{tabular}

(Hasil pengukuran)

Tabel 2. Data Pembacaan Dial Indikator

(Hasil pengukuran)

Tabel 3. Data Pengukuran Kelurusan

\begin{tabular}{|l|l|c|c|}
\hline \multicolumn{1}{|c|}{ Jarak } & \multicolumn{1}{|c|}{ Bulan\& Tahun } & Pompa 1 & Pompa 2 \\
\hline A (mm) & - & 210 & 210 \\
\hline B (mm) & - & 180 & 180 \\
\hline C $(\mathrm{mm})$ & - & 45 & 45 \\
\hline D (mm) & - & 75 & 75 \\
\hline E (mm) & - & 260 & 260 \\
\hline H $(\mathrm{mm})$ & - & 110 & 110 \\
\hline F (mm) & September 2016 & $+1,03$ & $+0,78$ \\
\cline { 2 - 4 } & Oktober 2016 & $+1,54$ & $+1,14$ \\
\hline F $(\mathrm{mm})$ & November 2016 & $+1,92$ & $+1,17$ \\
\hline Y (mm) & September 2016 & $+0,26$ & $+0,05$ \\
\cline { 2 - 5 } & Oktober 2016 & $+0,48$ & $+0,09$ \\
\hline Y (mm) & November 2016 & $+0,72$ & $+0,13$ \\
\hline
\end{tabular}

Data-data tersebut digunakan untuk melakukan perhitungan offset dan ketidaklurusan angular. Hasil perhitungan tersebut kemudian dibandingkan dengan batas toleransi yang menjadi acuan (Tabel 4). 
Tabel 4. Hasil Perhitungan dan Analisis Toleransi

\begin{tabular}{|c|c|c|c|c|c|c|}
\hline \multirow{2}{*}{ Plane } & \multicolumn{2}{|c|}{ Standart Toleransi Offset (mm) } & \multicolumn{2}{|c|}{ Nilai Offset (mm) } & \multicolumn{2}{|c|}{ Keterangan } \\
\hline & Excellent & Acceptable & Pompa 1 & Pompa 2 & Pompa 1 & Pompa 2 \\
\hline Verical & 0,03 & 0,07 & 0,36 & 0,065 & Tidak Masuk & Masuk \\
\hline Horizontal & 0.03 & 0.07 & 0.36 & 0.065 & Tidak Masuk & Masuk \\
\hline \multirow{2}{*}{ Plane } & \multicolumn{2}{|c|}{ Standart Toleransi Angular $(\mathrm{mm} / 100)$} & \multicolumn{2}{|c|}{ Nilai Angular $(\mathbf{m m} / 100)$} & \multicolumn{2}{|c|}{ Keterangan } \\
\hline & Excellent & Acceptable & Pompa 1 & Pompa 2 & Pompa 1 & Pompa 2 \\
\hline Verical & 0,04 & 0,07 & 0.97 & 0,609 & Tidak Masuk & Tidak Masuk \\
\hline Horizontal & 0,04 & 0,07 & 0,017 & 0,01 & Masuk & Masuk \\
\hline
\end{tabular}

Hasil analisis toleransi tersebut akan lebih tampak jika ditampilkan dalam bentuk grafik sebagai berikut :

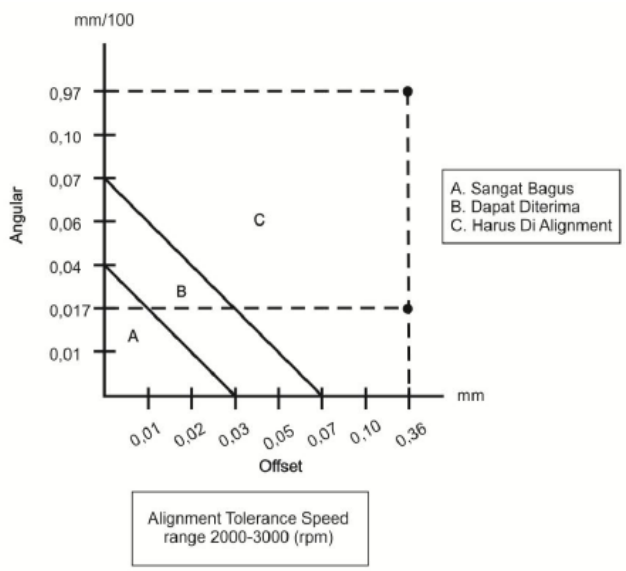

Gambar 2. Analisis kelurusan pompa 1

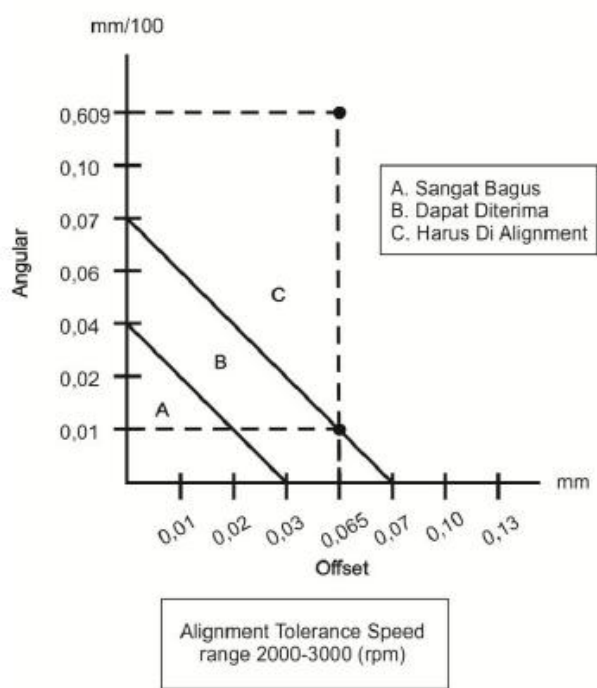

Gambar 3. Analisis kelurusan pompa 2

Dari tabel dan grafik analisis diatas diketahui bahwa nilai hasil perhitungan offset dan angular pada pompa satu (1), hanya nilai pada bidang horizontal saja yang masuk dalam batas toleransi yang diijinkan (acceptable) yaitu 0,017 mm. Sedangkan nilai perhitungan offset dan angular pada pompa dua (2), hanya nilai pada bidang vertikal saja yang tidak masuk dalam batas toleransi yang diijinkan (acceptable) yaitu 0,609 mm. Sehingga untuk memperbaiki ketidaklurusan atau mis-alignment tersebut perlu untuk dilakukan reposisi kaki-kaki motor pada pompa 1 dan pompa 2. Hasil hitungan reposisi adalah sebagai berikut :
Tabel 5. Hasil Perhitungan Reposisi Kaki Pompa dan Motor

\begin{tabular}{|c|c|c|c|c|}
\hline \multirow{2}{*}{ Deskripsi } & \multicolumn{2}{|c|}{ Pompa 1 } & \multicolumn{2}{c|}{ Pompa 2 } \\
\cline { 2 - 5 } & $\begin{array}{c}\text { Horizontal } \\
(\mathbf{m m})\end{array}$ & $\begin{array}{c}\text { Vertikal } \\
(\mathbf{m m})\end{array}$ & $\begin{array}{c}\text { Horizontal } \\
(\mathbf{m m})\end{array}$ & $\begin{array}{c}\text { Vertikal } \\
(\mathbf{m m})\end{array}$ \\
\hline Kaki Dalam Motor (IBdr) & $+4,64$ & $+3,5$ & $+2,26$ & $+1,97$ \\
\hline Kaki Luar Motor (OBdr) & $+6,87$ & $+4,28$ & $+4,49$ & $+2,45$ \\
\hline
\end{tabular}

Proses reposisi dilakukan dengan cara sebagaimana ditunjukkan pada Gambar 4 dan 5.
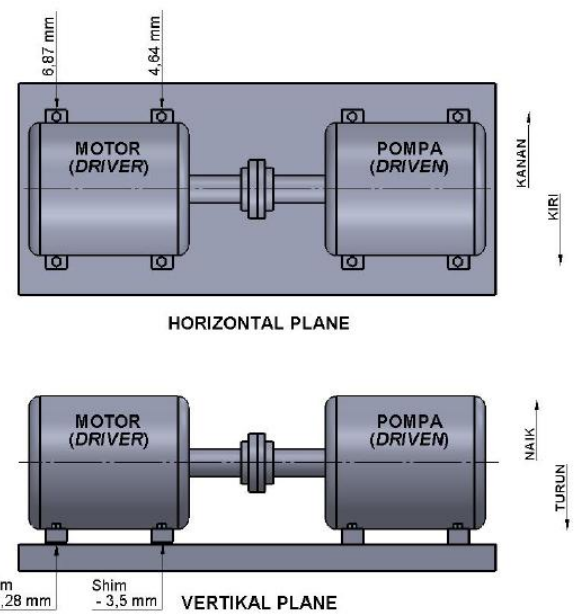

Gambar 4. Proses reposisi pompa 1
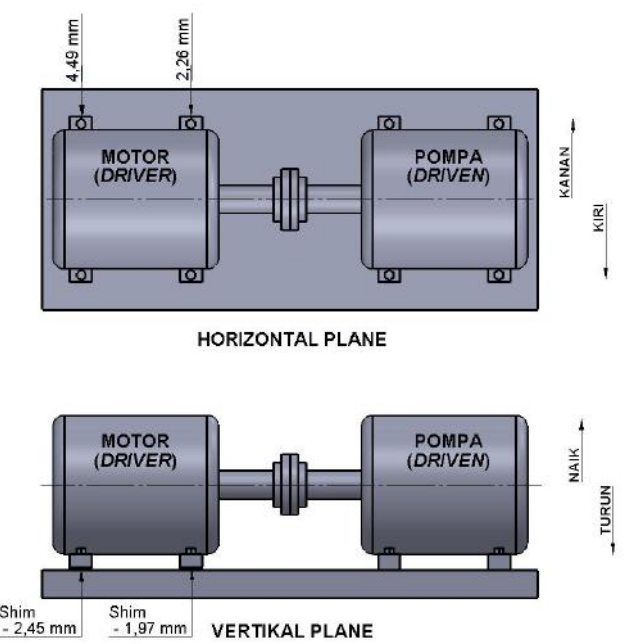

Gambar 5. Proses reposisi pompa 2

Dari hasil pengukuran dan perhitungan koreksi alignment menggunakan dial indikator serta hasil perbaikan reposisi pada kaki-kaki motor, maka selanjutnya dilakukan pengukuran dengan menggunakan metode penggaris dan feeler gauge sebagai perbandingan.

Metode penggaris ini digunakan untuk menentukan parallel gap antara poros motor dan poros pompa. Prinsipnya dengan mengandalkan ketelitian mata untuk menentukan penyimpangan alignment. Berikut contoh hasil dari pengukuran alignment menggunakan metode penggaris. 

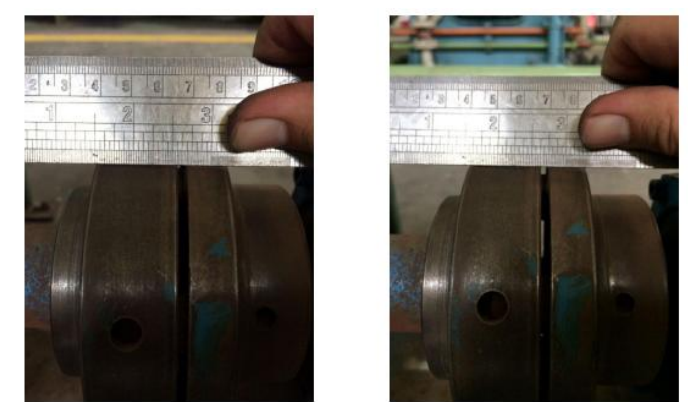

Gambar 6. Proses pengukuran dengan penggaris pada pompa 1 dan 2 .

Dari hasil pengukuran diatas dengan menggunakan metode penggaris pada pompa 1 dan pompa 2 didapati bahwa permukaan antara kopling motor dan kopling pompa rata terhadap penggaris, baik pada sisi kiri maupun sisi kanan kopling. Dengan demikian dapat diambil kesimpulan bahwa posisi antara poros motor dan poros pompa lurus dalam satu garis sumbu. Sehingga tidak perlu untuk dilakukan perbaikan alignment dengan melakukan reposisi pada kakikaki motor maupun pompa.

Metode feeler gauge dipakai untuk mengukur aksial gap kopling yang sempit. Prinsipnya dengan cara mengukur gap pada empat posisi jam 12, 3, 6, 9 (atas, kanan,bawah, kiri). Berikut contoh hasil dari pengukuran alignment menggunakan metode feeler gauge.

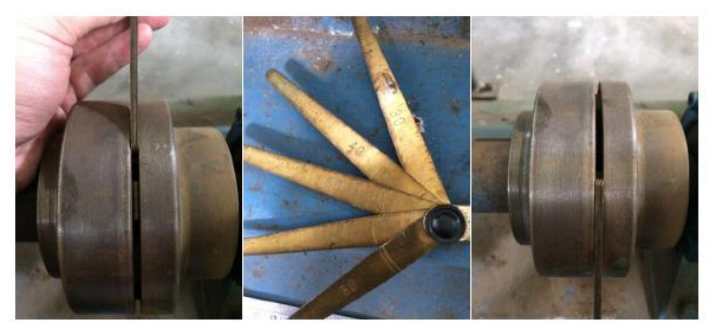

Gambar 7. Pengukuran dengan menggunakan feeler gauge pada pompa 1 dan 2

Dari hasil pengukuran diatas dengan menggunakan metode feeler gauge pada pompa 1 dan pompa 2 didapati bahwa gap antara sela kopling motor dan pompa pada ke empat posisi jam 12, 3, 6, 9 hasilnya sama yaitu untuk total tebal kaliper $2,8 \mathrm{~mm}$, dengan rincian per-kaliper 0,$3 ; 0,4 ; 0,6 ; 0,7$ dan 0,8. Dengan demikian dapat diambil kesimpulan bahwa posisi antara poros motor dan poros pompa lurus dalam satu garis sumbu. Sehingga tidak perlu untuk dilakukan perbaikan alignment dengan melakukan reposisi pada kaki-kaki motor maupun pompa.

\section{KESIMPULAN}

Berdasarkan hasil analisis pada pompa satu (1) diketahui bahwa nilai hasil perhitungan offset dan angular pada bidang vertikal yaitu 0,36 $\mathrm{mm}$ dan $0,97 \mathrm{~mm} / 100$. Sedangkan pada bidang horizontal nilainya yaitu $0,36 \mathrm{~mm}$ dan 0,017 $\mathrm{mm} / 100$. Hanya nilai angular $0,017 \mathrm{~mm} / 100$ pada bidang horizontal saja yang masuk dalam batas toleransi yang diijinkan.

Berdasarkan hasil analisis pada pompa dua (2) diketahui bahwa nilai hasil perhitungan offset dan angular pada bidang vertikal yaitu $0,065 \mathrm{~mm}$ dan $0,609 \mathrm{~mm} / 100$. Sedangkan pada bidang horizontal nilainya yaitu $0,065 \mathrm{~mm}$ dan $0,01 \mathrm{~mm} / 100$. Hanya nilai angular $0,609 \mathrm{~mm} / 100$ pada bidang vertikal saja yang tidak masuk dalam batas toleransi yang diijinkan.

\section{REKOMENDASI}

Mengingat sangat pentingnya dilakukan alignment antara poros motor dan poros pompa maka jangan menunggu terjadi kerusakan terlebih dahulu kemudian baru dilakukan perbaikan karena akan memakan waktu perbaikan lebih lama dan biaya perbaikan lebih besar. Adalah perlu untuk dilakukan pemeriksaan pre-alignment dan perbaikan secara berkala.

Gunakan metode sinar laser alignment untuk memperoleh data hasil pengukuran yang lebih cepat dan akurat serta praktis dalam proses pengoperasiannya, Daripada menggunakan metode dial indicator yang membutuhkan waktu untuk menganalisis hasil penyimpangan yang terjadi dengan menggunakan perhitunganperhitungan dengan rumus.

\section{DAFTAR PUSTAKA}

Adibroto, Soemarmo. 2005. Buku Panduan Praktis Alignment Mesin Rotasi. Trans Media, Jakarta. Chapter 2. Page 11 - 27

Piotrowski, John. 2007. Shaft Alignment Handbook Third Edition. The Ohio State University Columbus, USA. Chapter 3. Page $5-20$

Millwright. 2006. Dasar - Dasar Pelurusan dan Penyetelan Kerataan. Trans Media, Jakarta. Chapter 3. Page 1 - 10

Obengbaut. 2016. Type Mis-alignment. https://obengbaut.wordpress.com. diakses pada $18 / 10 / 2016$

Pendekarilusi. 2014. Alignment. http://www.pendekarilusi.com. diakses pada $18 / 10 /$

Zoair. 2013. Alignment Handout. http://www.alignmenthandout.com. diakses pada $18 / 10 / 2016$

Acoem. 2014. Rim And Face Metode Overview. http://www.alignmentknowledge.com. Diakses pada $20 / 10 / 2016$

Agung. 2012. Alignment Of Shaft By Dial Indikator. http://agung-jelantik.blogspot.co.id diakses pada 20/10/2016

Yulianto. 2016. Shaft Alignment. http://kvkvh.blogspot.co.id. diakses pada 23/10/2016 
Soesanto \& A. Farid (2018), PROTON, Vol. 10 No. 1/ Hal. 13 - 17

Aminudin. 2015. Toleransi Alignment. http://www.scribd.com diakses pada 25/10/2016

Fauzan. 2011. Laporan Kerja Praktek Shaft Alignment. http://www.scribd.com diakses pada $25 / 10 / 2016$

Piotrowski. 2013. The Importance of Shaft Alignment.

http://www.maintenanceresources.com/referen celibrary/alignment/importance.htm diakses pada $26 / 10 / 2016$
Testindo. 2014. Konfigurasi Mis-alignment. http://www.testindo.com/article/52/konfigurasi misalignment. diakses pada 26/10/2016

Vibrasindo. 2011. Kesejajaran Poros. http://www.vibrasindo.com/blogvibrasi/detail/ 43/apa-itukesejajaran-poros. diakses pada 27/10/2016

Maulana. 2012. Dial Tekan (Dial Indikator). https://www.scribd.com. diakses pada $27 / 10 / 2016$ 